\title{
JM
}

Volume 6 No. 1 (April 2018)

(C) The Author(s)

\section{GAMBARAN PENGETAHUAN DAN PARITAS IBU YANG MEMBERIKAN ASI EKSKLUSIF DI WILAYAH PUSKESMAS CAHAYA NEGERI KABUPATEN SELUMA TAHUN 2017}

\author{
DESCRIPTION OF MATERNAL KNOWLEDGE AND PARITY PROVIDING \\ EXCLUSIVE BREAST MILK AT CAHAYA NEGERI HEALTH CENTER OF \\ SELUMA REGENCY IN 2017
}

\begin{abstract}
DIYAH TEPI RAHMAWATI, TALIAH, LUCKY NELAZYANI, DAN AFRELIYA EKA. S DOSEN PRODI DIPLOMA III KEBIDANAN FIKES UNIVED BENGKULU MAHASISWA PRODI DIPLOMA III KEBIDANAN FIKES UNIVED BENGKULU Email : cecoatepay@gmail.com
\end{abstract}

\begin{abstract}
ABSTRAK
Penurunan angka pemberian ASI eksklusif merupakan salah satu faktor penyebab terjadinya kematian pada bayi. Bayi yang diberi susu, mempunyai risiko 17 kali lebih mengalami pneumonia, dan 3-4 kali lebih besar kemungkinan terkena ISPA dibandingkan dengan bayi yang mendapat ASI eksklusif (Maryunami, 2012).Penelitian ini bertujuan untuk mengetahui gambaran pengetahuan dan paritas ibu yang memberikan asi eksklusif Di Wilayah Puskesmas Cahaya Negeri Kabupaten Seluma Tahun 2017.Jenis penelitian adalah deskriptif kuantitatif dengan populasi seluruh Ibu yang memiliki bayi umur 6-12 bulan di Wilayah Puskesmas Cahaya Negri sebanyak 193 bayi. Penelitian ini dilakukan pada 18 Juni s/d 25 Juli 2017 dengan teknik pengambilan sampel Accidental Sampling yaitu sebanyak 66 responden. Penelitian ini menggunakan analisis deskriptif. Hasil penelitian didapatkan Dari 24 orang ibu yang memberikan ASI Eksklusif sebagian besar (54,2\%) berpengetahuan cukup dan sebagian besar $(54,2 \%)$ ibu dengan paritas multipara. Dari 42 orang ibu yang tidak memberikan ASI Eksklusif sebagian besar $(52,4 \%)$ berpengetahuan kurang dan sebagian besar $(59,5 \%)$ ibu dengan paritas primipara. Kepada puskesmas Cahaya Negeri Kabupaten Seluma diharapkan agar dapat bekerjasama dengan intansi kesehatan untuk dilakukan pemberian informasi kepada masyarakat khususnya ibu hamil maupun ibu yang mempunyai balita.
\end{abstract}

Kata kunci: ASI Eksklusif, Pengetahuan, Paritas

\begin{abstract}
The decline in the rate of exclusive breastfeeding is one of the factors causing death in infants. Breast-fed infants are 17 times more likely to have pneumonia, and are 3-4 times more likely to get respiratory infection than infants exclusively breastfed (Maryunami, 2012). This study aimed to determine the description of knowledge and parity of mothers providing exclusive ation at Cahaya Negeri health center of Seluma regency in 2017.The type of research is descriptive quantitative with the entire population of Mothers having infants aged 6-12 months at Cahaya Negri health center area as many as 193 babies. This research was conducted on June 18 to July 25, 2017 with the Accidental Sampling by 66 respondents. This research used a descriptive analysis. The results obtained from 24 mothers who gave exclusive breastfeeding, (54.2\%) were
\end{abstract}


knowledgeable enough and (54.2\%) mothers were with multiparity parity. Of the 42 mothers who did not breastfeed Exclusively (52.4\%) had less knowledge and most $(59.5 \%)$ of the mothers were with primiparity parityTo Cahaya Negeri Seluma Health Center of Seluma regency is expected to cooperate with health institute to do giving information to the community, especially pregnant women and mothers who have a toddler.

\section{Keywords: Exclusive Breast Milk, Knowledge, Parity}

\section{PENDAHULUAN}

Dalam upaya pencapaian derajat kesehatan yang optimal untuk meningkatkan mutu kehidupan bangsa, keadaan gizi yang baik merupakan salah satu unsur penting. Pertumbuhan dan perkembangan anak yang optimal di tahun pertama kehidupan sangat menentukan kualitas sumber daya manusia di sepanjang kehidupan. Salah satu faktor yang mempengaruhi pertumbuhan dan perkembangan adalah ASI sebagai satusatunya gizi bagi bayi 0-6 bulan (Kemenkes RI, 2015).

Dampak yang dapat ditimbulkan akibat dari tidak diberikannya ASI Eksklusif sama saja dengan membuka pintu gerbang masuknya berbagai jenis kuman. Hasil riset terakhir dari peneliti Indonesia menunjukkan bahwa bayi yang mendapatkan makanan selain ASI sebelum berumur 6 bulan, lebih banyak terserang diare, dan batuk pilek (ISPA) dibandingkan bayi yang hanya mendapatkan ASI eksklusif. Resiko pada pemberian sebelum umur tersebut dapat menimbulkan kenaikan berat badan yang terlalu cepat (obesitas) hingga menjurus ke obesitas (Nurulia, 2015).

Bayi yang tidak mendapat zat kekebalan pada ASI sangat rentan akan infeksi, yang dalam jangka waktu lama akan berakibat kekurangan gizi yang dapat terjadi apabila susu formula tidak diberikan sesuai dengan petunjuk penggunaan, selain itu dapat terjadi gangguan tumbuh kembang, serta resiko terjadinya kematian lebih tinggi (Marliandiani, 2015).

Menurut World Health Organization (WHO) tahun 2012, setiap tahun terdapat 11,5 juta bayi di dunia yang meninggal karena tidak diberi ASI. Pada tahun 2011 jumlah kematian neonatal ada 180 kasus. ASI
Eksklusif memiliki kontribusi yang besar terhadap tumbuh kembang dan daya tahan tubuh anak. Anak yang diberi ASI Eksklusif akan tumbuh dan berkembang secara optimal dan tidak mudah sakit. Kajian global "The Lancet Braestfeeding Series 2016" telah membuktikan bahwa menyusui eksklusif menurunkan angka kematian karena infeksi sebanyak $88 \%$ pada bayi berusia kurang dari 3 bulan, dan kematian anak karena kekurangan gizi sebanyak 2,7\%, karena tidak menerima ASI Ekslusif. Selain kematian bayi, akibat dari tidak diberikannya ASI eksklusif dapat menimbulkan diare sebanyak $67 \%$, ISPA sebanyak $39 \%$, serta risiko obesitas sebanyak 42\%. (Kemenkes RI, 2015).

Rencana Pembangunan Jangka Menengah Nasional (RPJMN) 2015-2025 untuk mewujudkan pembangunan kesehatan dan kesejahteraan masyarakat dengan menetapkan 3 strategi standarisasi Nasional, tiga diantaranya yang terkait dengan pemberian ASI eksklusif yaitu menurunkan angka kematian bayi menjadi 24 per 1000 kelahiran hidup, menurunkan angka kematian ibu menjadi 228 per 100 ribu kelahiran hidup, dan menurunkan prevalensi gizi kurang menjadi $15 \%$ dan balita pendek menjadi $32 \%$ (Kemenkes, 2015).

Data Riset Kesehatan Dasar (Riskesdas) tahun 2013 menunjukkan pemberian ASI di Indonesia yaitu bayi yang menyusu eksklusif sampai 6 bulan hanya 15,3\%. Penyebab rendahnya pemberian ASI ini adalah faktor sosial budaya, kurangnya pengetahuan ibu akan pentingnya ASI, serta sarana kesehatan yang belum sepenuhnya mendukung peningkatan pemberian ASI (Riskesdas, 2013).

Upaya untuk mendukung peningkatan pemberian ASI Eksklusif dapat dilihat dari telah dikeluarkannya berbagai pengakuan atau 
kesepakatan baik yang bersifat global maupun nasional yang bertujuan melindungi, mempromosi, dan mendukung pemberian ASI. Dengan demikian, diharapkan setiap ibu di seluruh dunia dapat melaksanakan pemberian ASI dan setiap bayi diseluruh dunia memperoleh haknya mendapat ASI. Sesuai dengan tujuan Sustainable Development Goals (SDGs) ke-3 target ke-2 yaitu pada tahun 2030, mengakhiri kematian bayi dan balita yang dapat dicegah, dengan seluruh negara berusaha menurunkan Angka Kematian Neonatal setidaknya hingga 12 per 1.000 Kelahiran Hidup.

Tingkat pengetahuan ibu tentang pemberian ASI, paritas ibu, dukungan suami dan keluarga serta tenaga kesehatan merupakan faktor penting berhasil tidaknya keberhasilan menyusui secara eksklusif. Berdasarkan Journal Of Nutrition And Food Research 2013 hampir sebagian ibu menyusui mempunyai pengetahuan tinggi $(49,8 \%)$, ibu tidak ada motivasi untuk memberikan ASI eksklusif $(35,9 \%)$, dan tidak mendapatkan dukungan dari keluarga $(36,8 \%)$ (Kemenkes, 2015).

Data Profil Dinas Kesehatan Provinsi Bengkulu tahun 2016 di Bengkulu Selatan jumlah bayi 2.823, Rejang Lebong jumlah bayi 4921, Bengkulu Utara jumlah bayi 5929, Kaur jumlah bayi 2616, Seluma jumlah bayi 3491, Muko-Muko jumlah bayi 5670, Lebong jumlah bayi 2212, Kepahiang jumlah bayi 2787, Bengkulu Tengah jumlah bayi 2565, Kota Bengkulu jumlah bayi 6876 (Dinkes Provinsi Bengkulu, 2016).

Data Profil Dinas Kesehatan Kabupaten Seluma dari 22 Puskesmas yang ada di Kabupaten Seluma, cakupan pemberian ASI yang tidak Eksklusif pada tahun 2016 sebanyak 996 bayi dengan angka pemberian ASI tidak Eksklusif tertinggi berada pada Puskesmas Sukamerindu yang mencapai 156 bayi dari 259 jumlah bayi, selanjutnya tertinggi kedua berada pada Puskemas Cahaya Negeri yaitu dari 343 jumlah bayi terdapat 130 bayi yang tidak mendapat ASI Eksklusif dan tertinggi ketiga berada pada Puskemas Rimbo Kedui dari 202 jumlah bayi terdapat sebanyak 123 bayi yang tidak mendapat ASI Eksklusif (Dinkes Seluma, 2016).

Hasil Survey awal yang dilakukan peneliti pada tanggal 24 April 2017 didapatkan jumlah Ibu yang memiliki bayi umur 6-12 bulan di Wilayah Puskesmas Cahaya Negri Provinsi Bengkulu sebanyak 193 bayi. Sedangkan hasil wawancara terhadap ibu yang mempunyai bayi usia 6-12 bulan meliputi pengetahuan ibu tentang pemberian ASI eksklusif pada bayi 0-6 bulan, dari 9 ibu yang memiliki bayi usia 6-12 bulan terdapat 4 ibu yang memberikan ASI ekslusif yang terdiri dari 2 orang berpengetahuan cukup dengan paritas primipara dan 2 orang berpengetahuan baik dengan paritas multipara. Sedangkan 5 orang ibu yang tidak memberikan ASI Eksklusif dengan alasan sibuk bekerja, ASI sedikit, dan putting susu tidak keluar terdapat 3 orang ibu yang memiliki pengetahuan cukup tentang ASI dengan paritas primipara, dan 2 orang ibu berpengetahuan kurang tentang manfaat ASI dengan paritas grandemultipara.

Peneliti dengan judul Gambaran Pengetahuan dan Paritas Ibu yang memberikan ASI Eksklusif di Wilayah Puskesmas Cahaya Negeri Kabupaten Seluma Provinsi Bengkulu. Penelitian ini dapat diterapkan secara mudah, praktis, dan dapat diterapkan sesuai kewenangan bidan, efisien dan efektif.

Berdasarkan latar belakang dan survei awal yang dilakukan peneliti, maka peneliti bermaksud untuk mengadakan penelitian lebih lanjut dengan judul "Gambaran Pengetahuan dan Paritas Ibu yang memberikan ASI Eksklusif di Wilayah Puskesmas Cahaya Negeri Kabupaten Seluma Provinsi Bengkulu".

Tujuan penelitian ini adalah untuk mengetahui gambaran pengetahuan dan paritas ibu yang memberikan ASI Eksklusif di Wilayah Puskesmas Cahaya Negeri Kabupaten Seluma Provinsi Bengkulu tahun 2017. 
METODE

\section{Desain, waktu dan tempat}

Desain penelitian yang digunakan dalam penelitian ini adalah metode pendekatan cross sectional ini digunakan sebagai suatu bentuk penelitian yang bertujuan untuk menggambarkan atau menganalisis antara variabel penelitian paritas dan pengetahuan Ibu terhadap pemberian ASI Eksklusif. Tempat penelitian ini akan dilaksanakan di Wilayah Kerja Puskesmas Cahaya Negri Kabupaten Seluma Provinsi Bengkulu dan dilaksanakan pada tanggal 1825 Juli 2017.

\section{Jenis dan cara pengumpulan data}

Penelitian ini dikumpulkan dengan cara pengumpulan data primer yaitu melalui kuesioner yang dibagikan kepada ibu yang mempunyai bayi yang berusia 6 sampai 12 bulan yang sedang mengikuti kegiatan posyandu di Puskesmas dengan daftar pertanyaan terstruktur untuk mengetahui pengetahuan, paritas dan ASI Eksklusif. Sebelumnya Responden diberi penjelasan terlebih dahulu cara pengisian kuesioner tersebut.

1. Peneliti mengambil data awal responden dari Puskesmas

2. Peneliti melakukan survey awal kepada 9 orang respoden untuk menunjang data penelitian

3. Peneliti melakukan studi pendahuluan dengan wawancara dan observasi serta mengumpulkan data awal seperti jumlah responden minimal selama 3 bulan terakhir.

4. Penelitian berada di Puskesmas selama 8 hari saat jam kerja.

5. Peneliti melakukan penelitian di Puskesmas, sebelumnya peneliti memberikan penjelasan dan tujuan mengenai penelitian ini bersifat suka rela dan dijaga kerahasiaannya.

6. Peneliti mengidentifikasi reponden ibu dari bayi usia $0-12$ bulan
7. Peneliti meminta responden menandatangani surat persetujuan menjadi responden.

8. Peneliti di bantu Puskesmas melakukan penelitian.

\section{Pengolahan dan Analisis Data}

Pengolahan data dilakukan setelah pengumpulan data selesai, adapun langkah dalam pengolahan data yaitu melakukan pemeriksaan daftar pertanyaan yang telah diserahkan oleh para pengumpul data. Memilih atau menyortir data sedemikian rupa sehingga hanya data yang dipakai saja yang tinggal. Tujuannya adalah mengurangi kesalahan atau kekurangan yang ada di daftar pertanyaan. Hal ini bermaksud untuk merapikan data agar bersih, rapi dan tinggal mengadakan pengelolahan lanjutan selanjutnya mengklarifikasikan jawaban dari para responden ke dalam kategori. Data yang disusun dan telah diperiksa kelengkapannya kemudian dikelompokan atau digolongkan berdasarkan kategori yang dibuat berdasarkan justifikasi atau pertimbangan peneliti sendiri. Pernyataan yang diberikan skor hanya pertanyaan yang berhubungan dengan pengetahuan dan Paritas Ibu terhadap pemberian ASI Eksklusif tahap ini meliputi nilai untuk masing-masing pertanyaan dan penjumlahan hasil scoring dari semua pertanyaan selanjutnya memasukan data yang telah dikumpulkan kedalam Master Tabel atau base computer, kemudian membuat distribusi frekuensi sederhana atau bias juga membuat tabel konfigensi langkah terakhir yaitu melakukan pengecekan kembali data yang dimasukkan dilakukan bila terdapat kesalahan dalam memasukkan data yaitu dengan melihat distribusi frekuensi tingkat pengetahuan dan Paritas Ibu.

Analisa data yang digunakan dalam penelitian ini adalah deskriptif dengan maksud untuk mendapatkan gambarkan distribusi frekuensi dari variabel yang diteliti. 
HASIL

Data yang diperoleh dalam penelitian ini dianalisis secara deskriptif untuk melihat gambaran Pengetahuan Paritas dan Pemberian ASI di Wilayah Kerja Puskesmas Cahaya Negeri Kabupaten Seluma. Selengkapnya hasil analisis disajikan dalam tabel sebagai berikut:

Tabel 1 Gambaran Pengetahuan Terhadap Pemberian ASI Eksklusif di Wilayah Puskesmas Cahaya Negeri Kabupaten Seluma Provinsi Bengkulu

\begin{tabular}{ccc}
\hline Variabel & Frekuensi & Persentasi (\%) \\
\hline Kurang & 24 & 36,4 \\
\hline Cukup & 26 & 39,4 \\
\hline Baik & 16 & 24,2 \\
\hline Total & 66 & 100,0 \\
\hline
\end{tabular}

Berdasarkan tabel 1 didapatkan bahwa dari 66 orang hampir sebagian dari responden yaitu 26 orang $(39,4 \%)$ berpengetahuan cukup, $24(36,4 \%)$ orang berpengetahuan kurang, dan sebagian kecil yaitu 16 orang $(24,2 \%)$ berpengetahuan baik.

Tabel 2 Gambaran Paritas Terhadap Pemberian ASI Eksklusif di Wilayah Puskesmas Cahaya Negeri Kabupaten Seluma Provinsi Bengkulu

\begin{tabular}{ccc}
\hline Variabel & Frekuensi & Persentasi (\%) \\
\hline Primipara & 33 & 50,0 \\
\hline Multipara & 21 & 31,8 \\
\hline Grandemultipara & 12 & 18,2 \\
\hline Total & 66 & 100,0 \\
\hline
\end{tabular}

Berdasarkan tabel 2 didapatkan bahwa dari 66 orang responden setengahnya yaitu paritas primipara sebanyak 33 orang $(50 \%)$, hampir sebagian dari responden yaitu 21 orang $(31,8 \%)$ dengan paritas multipara,dan sebagian kecil dari responden yaitu 12 orang $(18,2 \%)$ dengan paritas grandemultipara.

Tabel 3 Gambaran Pemberian ASI Eksklusif di Wilayah Puskesmas Cahaya
Negeri Kabupaten Seluma
Bengkulu

Provinsi

\begin{tabular}{ccc}
\hline Variabel & Frekuensi & Persentasi (\%) \\
\hline $\begin{array}{c}\text { Tidak ASI } \\
\text { Eksklusif }\end{array}$ & 42 & 63,6 \\
\hline ASI Eksklusif & 24 & 36,4 \\
\hline Total & 66 & 100,0 \\
\hline
\end{tabular}

Berdasarkan tabel 3 didapatkan bahwa dari 66 orang sebagian besar dari responden yaitu 42 orang $(63,6 \%)$ tidak memberikan ASI Eksklusif dan hampir sebagian dari responden yaitu 24 orang (36,4\%) memberikan ASI Eksklusif.

\section{PEMBAHASAN}

Gambaran Pengetahuan yang memberikan ASI Eksklusif di Wilayah Puskesmas Cahaya Negeri Kabupaten Seluma Provinsi Bengkulu

Berdasarkan hasil penelitian didapatkan bahwa dari 42 orang ibu yang tidak memberikan ASI eksklusif sebagian 22 ibu berpengetahuan kurang. Berdasarkan hasil wawancara didapatkan banyak ibu dengan pengetahuan kurang yang tidak mengerti apa itu ASI Eksklusif, sampai berapa umur bayi diberikan ASI eksklusif, serta manfaat ASI eksklusif itu sendiri bagi ibu dan bayi.

Selain itu dari 42 orang ibu yang tidak memberikan ASI eksklusif hampir sebagian $13 \mathrm{ibu}$ berpengetahuan cukup dan sebagian kecil $7 \mathrm{ibu}$ berpengetahuan baik. Ini karena ibu yang berpengetahuan cukup beralasan tidak sempat karena bekerja sebagai PNS dan kegiatan ibu yang padat di kantornya sehingga membuat dia tidak sempat memberikan ASI secara ekslusif kepada bayinya dan ada pula ibu yang mengatakan bayinya di titipkan kepada orang tuanya sehingga sering diberikan susu formula saat menangis. Sedangkan ibu yang berpengetahuan baik yang tidak memberikan ASI Eksklusif beralasan air susu ibu tidak keluar, produksi ASI sedikit/tidak cukup, puting susu kecil atau kedalam, ada juga ibu 
yang mengatakan sesudah di susui bayinya menangis, serta kepercayaan keluarga yang memberikan bayinya makanan seperti madu karena kebiasaan atau kebudayaan keluarga.

Penelitian ini sejalan dengan teori yang dikemukan oleh Notoatmodjo (2012) bahwa pengetahuan yang di peroleh seseorang akan dapat memberi pengaruh terhadap kemampuan dan daya pikir serta sikap seseorang yang kemudian diwujudkan ke dalam tindakan. Sedangkan menurut Harini (2009) menyatakan bahwa pengetahuan yang dapat mempengaruhi sikap, niat, dan prilaku seseorang adalah pengetahuan dari segi positif maupun segi negatif suatu hal. Jadi pengetahuan merupakan faktor yang penting dalam perubahan sikap dan prilaku. Pengetahuan yang baik tentang pentingnya memberikan ASI Eksklusif cenderung menciptakan sikap dan prilaku yang baik pula, demikian sebaliknya. Dengan memiliki pengetahuan yang baik, ibu menyusui akan memiliki perubahan prilaku pada pemberian ASI Eksklusif pada bayinya.

Penelitian ini sejalan dengan teori yang dikemukakan oleh Mubarak (2012), Pengetahuan adalah kesan didalam pikiran manusia sebagai hasil penggunaan pancainderanya, pengetahuan sangat berbeda dengan kepercayaan (beliefs), takhayul (superstition) dan penerangan-penerangan yang keliru (missinformation). Pengetahuan adalah segala apa yang diketahui berdasarkan pengalaman yang didapatkan oleh setiap manusia.

Menurut Baskoro (2008), ASI merupakan makanan yang pertama, utama, dan terbaik bagi bayi, yang berisfat alamiah, ASI mengandung berbagai zat gizi yang dibutuhkan dalam proses pertumbuhan dan perkembangan bayi. Terkait itu sangat disayangkan, yakni rendahnya pemahaman ibu, keluarga, dan masyarakat, yakni rendahnya pemahaman ibu, keluarga, dan masyarakat mengenai pentingnya ASI bagi bayi.
Gambaran Paritas Ibu yang memberikan ASI Eksklusif di Wilayah Puskesmas Cahaya Negeri Kabupaten Seluma Provinsi Bengkulu

Berdasarkan hasil penelitian didapatkan bahwa dari 42 orang ibu yang tidak memberikan ASI Eksklusif sebagian besar 25 orang ibu dengan paritas primipara. Hasil penelitian Kondisi ini menunjukkan tingginya angka ibu menyusui dengan paritas primipara yaitu ibu yang baru memiliki anak pertama, karena pola asuhan pada anak pertama bisa mempengaruhi psikis ibu dalam memberikan ASI kepada bayinya, serta kurangnya pengalaman ibu dalam mengkonsumsi makanan yang baik untuk memperlancar ASI, dan beberapa kasus juga ditemukan banyaknya gangguan kesehatan yang terjadi seperti air susu sedikit, dan putting tidak keluar. serta banyak pula ibu yang disibukkan dengan kegiatan diluar rumah seperti bekerja.

Selain itu dari 66 Ibu yang memiliki bayi umur 6-12 bulan hampir sebagian dari responden $21 \mathrm{ibu}$ dengan paritas multipara dan sebagian kecil 12 ibu dengan paritas grandemultipara Kondisi ini menunjukkan bahwa banyak ibu yang tidak memberikan ASI Eksklusif pada ibu dengan paritas multipara dan grandemulti ini karena ibu beralasan sibuk bekerja, air susu tidak keluar, dan bayi tidak puas diberi ASI saja. Sehingga ibu memilih memberikan makanan pendamping ASI sejak usia bayi $<6$ bulan.

Ini sejalan dengan teori Dahlan (2012), ibu yang tidak memberikan ASI ekslusif pada anaknya di sebabkan banyak faktor, yaitu pengetahuan ibu yang rendah atau yang baik tetapi karena kesibukan yang memakan waktu ekstra seperti ibu yang bekerja di luar, sehingga ibu tidak sempat memberikan ASI secara eksklusif.

Paritas adalah keadaan seorang ibu yang melahirkan janin lebih dari satu orang . paritas merupakan status seorang wanita berhubungan dengan jumlah anak yang pernah dilahirkannya, ibu yang baru pertama kli hamil merupakan hal yang sangat baru sehingga termotivasi dalam memeriksakan 
kehamilannya ke tenaga kesehatan. Sebaliknya yang sudah melahirkan lebih dari satu orang yang mempunyai anggapan bahwa ia sudah berpengalaman sehingga tidak termotivasi untuk memeriksakan kehamilannya (Sarwoso, 2010).

\section{Gambaran ASI Eksklusif di Wilayah Puskesmas Cahaya Negeri Kabupaten Seluma Provinsi Bengkulu}

Berdasarkan hasil penelitian dari $66 \mathrm{Ibu}$ yang memiliki bayi umur 6-12 bulan sebagian besar $63,6 \%$ ibu tidak memberikan ASI Eksklusif. Kondisi ini menunjukkan masih rendahnya angka kejadian ibu yang memberikan ASI ekslusif pada anaknya, berdasarkan wawancara yang dilakukan banyak ibu yang tidak mengetahui apa keuntungan bila ibu menyusui bayi secara eksklusif, manfaat menyusui bagi ibu sendiri, tidak mendapatkan informasi kesehatan tentang pentingnya ASI eksklusif dan sibuk bekerja.

Penelitian ini sejalan dengan teori yang dikemukan oleh Khasanah, (2011), ASI Eksklusif adalah Pemberian ASI saja pada bayi sampai usia 6 bulan tanpa tambahan makanan lainnya ataupun cairan lainnya seperti susu formula, jeruk, madu, teh, air putih dan tanpa tambahan makanan padat apapun seperti pisang, pepaya, bubur susu, biskuit, bubur nasi dan tim sampai usia enam bulan. Menurut WHO menyarankan bahwa ASI Eksklusif selama 6 bulan pertama hidup bayi adalah yang terbaik.

Di dukung juga oleh pendapat Kemenkes RI (2012), Air Susu Ibu (ASI) adalah makanan terbaik dan alamiah untuk bayi. Menyusui merupakan suatu proses alamiah, namun sering ibu-ibu tidak berhasil menyusui atau menghentikan menyusui lebih dini sebelum usia enam bulan. Oleh karena itu ibu-ibu memerlukan bantuan agar proses menyusui ASI Eksklusif berhasil. Banyak alasan yang dikemukan ibu-ibu antara lain, ibu merasa bahwa ASInya tidak cukup, ASI tidak keluar pada hari-hari pertama kelahiran bayi. Sesungguhnya hal itu disebabkan karena ibu tidak percaya diri bahwa ASI nya cukup untuk bayinya. Kurangnya Informasi tentang cara-cara menyusui yang baik dan benar, pemberian ASI Eksklusif belum menjangkau sebagian besar ibu-ibu.

Penelitian ini sejalan dengan penelitian yang dilakukan oleh Dian, (2013) Faktorfaktor yang berhubungan dengan pemberian ASI Eksklusif di Kelurahan Palebon kecamatan Pedurungan Kota Semarang. Didapatkan hasil penelitian adanya hubungan antara faktor pengetahuan, pekerjaan, dan sikap ibu terhadap pemberian ASI Eksklusif dengan nilai $\mathrm{p}=0,003$

\section{KESIMPULAN}

Berdasarkan hasil penelitian tentang gambaran pengetahuan dan paritas ibu yang memberikan ASI Eksklusif di Wilayah Puskesmas Cahaya Negeri Kabupaten Seluma Provinsi Bengkulu dapat disimpulkan :

1. Dari 66 orang responden hampir sebagian dari responden $26(39,4 \%)$ berpengetahuan cukup

2. Dari 66 orang responden setengah dari responden $33(50,0 \%)$ dengan paritas primipara.

3. Dari 66 orang responden sebagian besar dari responden $42 \quad(63,6 \%)$ tidak memberikan ASI Eksklusif.

\section{SARAN}

1. Bagi Puskesmas Cahaya Negeri

Diharapkan pada petugas kesehatan di Puskesmas Cahaya Negeri agar petugas kesehatan khususnya perawat agar dapat memberikan penyuluhan dan promosi kesehatan pada ibu dan keluarga baik di bidan praktek mandiri (BPM) atau posyandu tentang apa itu ASI eksklusif dan bagaimana cara menyimpan ASI saat bekerja dan meminumkannya ke bayi walau tidak dari puting ibu, serta efek samping yang bisa di timbulkan pada pertumbuhan anak yang diberikan makanan terlalu cepat sebelum ASI eklusif 
diberikan sampai 6 bulan. Serta bagi keluarga terutama suami agar tetap memberikan motivasi kepada ibu untuk selalu memberikan ASI eksklusif sampai bayi berusia 6 bulan. Selain itu. peran Puskesmas juga sangat berperan penting dalam keberhasilan pemberian ASI eksklusif dengan cara Puskesmas harus melaksanakan program penyuluhan serta pembagian famplet untuk informasi kesehatan terkait ASI eksklusif.

2. Bagi Akademi Kebidanan Dehasen

Diharapkan pihak dari akademik menambah referensi tentang pengetahuan dan paritas ibu yang memberikan ASI Eksklusif karena dalam penyusunan KTI ini penulis sangat kesulitan dalam mencari referensi, sehingga diharapkan pada pihak akademik untuk penambahan pustaka baru tentang ASI Eksklusif. Untuk kelangsungan peneliti selanjutnya.

\section{Bagi Peneliti}

Bagi peneliti lain agar dapat melakukan penelitian selanjutnya dengan mengembangkan penelitian ini menggunakan variabel lainnya yang mempengaruhi pemberian ASI Ekslusif, seperti dukungan suami/keluarga, sikap, sosial budaya, gangguan produksi ASI, dan cara pemberian ASI

\section{DAFTAR PUSTAKA}

Ambarwati, E. R., Wulandari, D. (2010). Asuhan Kebidanan Nifas. Yogyakarta: Nuha Medika.

Amira, G. (2010). Pentingnya paritas pada rencana kehamilan. Jakarta: Salemba Medika

Arikunto (2006) Buku Acuan Nasional Pelayanan Kesehatan Maternal dan Neonatal, Jakarta : Yayasan Bina Pustaka

Dahlan. G, (2012). Buku Ajar Asuhan Kebidanan pada Ibu Nifas.Yogyakarta: C.V Andi Offset.

Dinas Kesehatan Provinsi Bengkulu. 2016.
Profil Kesehatan Kota Bengkulu. Tahun 2016, Bengkulu.

Dinas Kesehatan Kabupaten Seluma. (2016). Data Ibu Pemberian ASI Eksklusif dan Bayi Umur 0-6 Bulan Di Wilayah Kerja Puskesmas Cahaya Negeri 2016

Data Puskesmas Chaya Negeri Kabupaten Seluma tahun 2016

Judistiani, K. (2015). Pentingnya ASI untuk kesehatan bayi. Jakarta. Salemba Medika.

Kemenkes R.I. (2015). Peraturan Pemerintah Republik Indonesia Nomor 33 Tahun 2012 tentang Pemberian Air Susu Ibu Eksklusif.

Keraf, E. (2001). Konsep dasar Pengetahuan. Jakarta: Salemba Medika

Marliandiani, Y. (2015). Asuhan Kebidanan Pada Masa Nifas Dan Menyusui. Jakarta: Salemba Medika.

Maryunami, A. (2012). Inisiasi Menyusui Dini, ASI Eksklusif dan manajemen laktasi. Jakarta: Trans Info Media

Mulyani, A. (2013). Ilmu Kesehatan Anak. Jakarta: Trans Info Medika.

Nugroho, T. (2011). Asuhan Kebidanan Nifas. Yogyakarta: Nuha Medika.

Notoatmodjo, S. (2011). Kesehatan Masyarakat Ilmu Dan Seni. Jakarta: Rineka Cipta.

Notoatmodjo, S. (2010). Promosi Kesehatan Teori Dan Aplikasinya. Jakarta: Rineka Cipta.

Prameta, H. (2012). Konsep Dasar Paritas: Yogyakarta: Nuha Medika

Purwoastuti, dkk. (2015). Asuhan Kebidanan Masa Nifas Dan Menyusui. Yogyakarta: Pustaka Baru Press.

Rizki, L. (2013) Masa Nifas. Jakarta : Pustaka Baru Press

Riskesdas, (2013). Badan Penelitian dan Pengembangan Kesehatan Kementerian Kesehatan RI. Jakarta

Roesli, U. (2009). Mengenal ASI Eksklusif. Yogyakarta: Puspa Suara

Saifuddin, I. (2010). Buku Ajar Asuhan Kebidanan Neonatus. Bayi, Dan Anak Balita. Yogyakarta: Nuha Medika.

Sarwoso, P. (2010). Asuhan Kebidanan 
Neonatus, Bayi dan Balita. Surabaya : Rineka Cipta

Walyani. (2015). Asuhan Kebidanan Masa

Nifas Dan Menyusui. Yogyakarta:

Pustaka Baru Press. 